\title{
Status Sociométrico em Adolescentes na Transição para o Segundo Ciclo do Ensino Fundamental
}

\section{Sociometric Status in Adolescents in the Transition to the Second Cycle of Elementary School}

\author{
Fatima Almeida Maia (orcid.org/0000-0002-7035-3405) ${ }^{1}$ \\ Adriana Benevides Soares (orcid.org/0000-0003-2892-1808)2 \\ Marcia Cristina Monteiro (orcid.org/0000-0003-3455-2690) ${ }^{3}$
}

\begin{abstract}
Resumo
O objetivo do estudo foi identificar e comparar o status sociométrico de estudantes que passam pela transição do primeiro para o segundo ciclo do Ensino Fundamental. Participaram 258 alunos, sendo 142 do $6^{\circ}$ ano, idades entre 10 e 13 anos $(M=11,62 ; D P=0,88)$ e 116 do $7^{\circ}$ ano, com idades entre 13 e 15 anos $(M=12,75 ; D P=0,90)$. A coleta de dados deu-se por meio do Protocolo de Indicação Sociométrica. Os resultados permitiram identificar as posições dos estudantes no grupo e as peculiaridades dos alunos do $6^{\circ}$ ano, que receberam mais atribuições de comportamentos de rejeição, de popularidade, controversos e negligenciados do que os do $7^{\circ}$ ano. No $7^{\circ}$ ano os alunos já desenvolveram alguns aspectos afetivos e sociais que facilitam as relações. O estudo contribui com dados sobre o convívio interpessoal na transição no Ensino Fundamental, propiciando ações pedagógicas, interacionais e de aprendizagem mais adequadas à adaptação escolar.
\end{abstract}

Palavras-chave: Status sociométrico. Adolescentes. Relações interpessoais.

\begin{abstract}
The objective of the study was to identify and compare the sociometric status of students who gothrough the transition from the first to the second cycle of Elementary School. 258 students participated, being 142 of the 6th grade, aged between 10 and 13 years $(M=11.62, S D=0.88)$ and 116 of the 7 th grade, aged between 13 and 15 years $(M=12.75$, $S D=0.90)$. Data were collected through the Sociometric Indication Protocol. The results allowed to identify the

\footnotetext{
${ }^{1}$ Universidade Salgado de Oliveira, Rio de Janeiro, Brasil. E-mail: maiafalmeida@gmail.com.

2 Universidade Salgado de Oliveira; Universidade do Estado do Rio de Janeiro, Rio de Janeiro, Brasil. E-mail: adribenevides@gmail.com.

${ }^{3}$ Universidade Salgado de Oliveira, Rio de Janeiro, Brasil. E-mail: marcialauriapsi@outlook.com.
} 
students' positions in the group and the peculiarities of those in the sixth grade, who received more attributions of rejection, popularity, controversial and neglected behaviors than the seventh grade students. In the 7th grade, students have already developed some affective and social aspects that facilitate relationships. The study contributes with data on interpersonal coexistence in the transition in Elementary School, providing pedagogical, interactional and learning actions more appropriate to school adaptation.

Keywords: Sociometric status. Adolescents. Interpersonal relationships. 


\section{Introdução}

Ser promovido para as séries correspondentes ao Fundamental II implica em uma grade curricular separada por diferentes componentes (Matemática, Português, Educação Física, entre outros) e com professores e horários específicos para cada componente. Além disso, há mudança no ambiente físico, psicológico e social, haja vista que muitas escolas não oferecem o Fundamental II, o que exige a busca por uma nova instituição. Dessa forma, a passagem do estudante de um segmento para o outro pode ser vivenciada como uma ruptura de ambiente e de práticas pedagógicas.

Assim, o ingresso no $6^{\circ}$ ano de escolaridade é motivo de preocupação para educadores que vivenciam em seu cotidiano transformações e desafios dessa faixa etária. Há uma distância nas relações, caracterizada, por exemplo, pelo maior número de docentes e mesmo uma crise de descontinuidade, promovida pela mudança de instituição, de localidade, de novas relações com pares, gestores, das diferentes práticas docentes, o que pode causar transtornos e sofrimentos (Barbosa, 2008). Essa transição traz momentos muito difíceis de adaptação, pois além do rendimento escolar, o aluno precisa aceitar regras novas, colaborar com os amigos, respeitar o espaço escolar para que sua adaptação ao ambiente com características bastante diferenciadas em nível social, emocional e físico, favoreça sua permanência e seu sucesso na escola (Cia \& Costa, 2012).
Quando o indivíduo exibe um baixo repertório de habilidades sociais, pode encontrar dificuldades de aprendizagem e comportamentais, com prejuízos no rendimento escolar e o surgimento de comportamentos antissociais, vivenciando momentos críticos que dificultam a adaptação e a apreensão de novas experimentações (Cia \& Costa, 2012). As demandas que ocorrem na passagem de uma escola para outra, bem como de um segmento a outro, exigem que o estudante incorpore novas habilidades sociais ao seu repertório, no intuito de lidar com uma diversidade de experiências e entender o estar no mundo (Del Prette \& Del Prette, 1999) e no contexto em que se insere.

Muitos desafios estão presentes no processo de socialização dos estudantes. A capacidade de interação consiste em se ajustar às expectativas do professor e em responder às perspectivas dos colegas, aprendendo a ter bons relacionamentos e a experimentá-los no grupo (Del Prette \& Del Prette, 2003). A socialização é uma das principais tarefas de desenvolvimento inicial da criança que amplia e aprimora o repertório de comportamentos sociais, fazendo com que o indivíduo entenda de forma gradativa os valores e normas culturais que estão presentes na vida em sociedade (Del Prette \& Del Prette, 2009; Neves, Castanheira \& Gouvêa, 2015).

Observa-se que quando o indivíduo expõe dificuldades nas relações interpessoais, ele tende a apresentar deficit de comportamento ocasionando problemas de natureza comportamentais e emocionais (Stevanato, Loureiro, Linhares \& 
Marturano, 2003). As dificuldades em lidar com as novas situações podem repercutir em comportamentos agressivos ou antissociais, como um dos fatores preditivos que comprometem o desenvolvimento socioemocional e de habilidades sociais de crianças e adolescentes (Del Prette \& Del Prette, 2003). O termo antissocial se refere a quando o indivíduo demonstra baixa competência, isolamento, oposição às normas estabelecidas, uso inadequado de processos de interação, não conseguindo resolver os problemas de forma autônoma (Pavarino, Del Prette \& Del Prette, 2005). Portanto, comportamentos que apresentam baixo repertório de habilidades sociais e que impedem o desenvolvimento de competências sociais necessárias a um bom relacionamento podem levar o adolescente a experimentar problemas em diversas áreas sociais (Camargo \& Bosa, 2009; Ruegg, 2003). Assim, os autores afirmam que o adolescente que se relaciona pouco com os outros e apresenta repertórios deficientes de habilidades sociais compromete o mundo acadêmico, deixando de expressar, na maioria das vezes, suas necessidades diante do processo de ensino e aprendizagem, inibindo sua interação em outras situações acadêmicas, dificultando ações que renovem as relações sociais na construção de sua independência e sucesso (Ruegg, 2003). Ainda, segundo o autor, o domínio da competência social relaciona-se diretamente ao sucesso acadêmico, o que pode gerar problemas emocionais e comportamentos antissociais, causando abandono e desistência do ambiente escolar.

É importante perceber que a competência social contribui para um desenvolvimento mais eficaz do indivíduo e seus pares, mantendo relações positivas que melhorem sua inserção no ambiente, utilizando estratégias que garantam sua posição no grupo (Mota, Matos \& Lemos, 2011). As autoras ainda enfatizam que, desde cedo, as crianças manifestam a necessidade de interagir, considerando mais importante ainda serem aceitos em suas interações. A competência social envolve, portanto, comportamentos aceitáveis que ajudam os adolescentes na descoberta de relações com os adultos e com seus pares. Em relação à aceitação pelos pares, Elliot, Sheridan e Gresham (1989) incluem juízos positivos de habilidades sociais reforçados pelos pais e professores, competência acadêmica, autoconceito e autoestima elevados, ajudando na aquisição de resultados sociais valorizados nas relações interpessoais. Segundo Del Prette e Del Prette (2011, p. 20), a competência social é um "atributo avaliativo de um comportamento ou episódio de comportamentos bem-sucedidos no ambiente social". Os autores entendem que o construto é operacional a partir do momento que cumpre requisitos como atingir um objetivo específico, melhoria na qualidade das interações sociais, compreensão e equilíbrio das relações. Portanto, é um construto com múltiplas dimensões, que comprende fatores sociais, interpessoais, cognitivos e emocionais (Lemos \& Meneses, 2002).

Segundo Castro, Melo e Silvares (2003), Cole e Cole (2003) e Holfve-Sabel (2014), quando a criança amplia suas experiências sociais e passa grande parte do tempo no convívio com o outro, precisa aprender a manter um lugar aceitável no 
grupo para melhor se adaptar. Por outro lado, a aceitação pelos pares torna-se importante para a construção do conceito sobre si mesma, para seu desenvolvimento, ampliando sua capacidade de considerar pontos de vistas diferentes, criando oportunidades de relações indispensáveis para a ampliação das habilidades sociais. Ainda, de acordo com os autores, nessa fase, surge uma estrutura social que vai delimitando as posições que ocupa com os companheiros, a experimentação e as estratégias para exercer o poder, produzindo comportamentos que são apreciados pelos outros, que apresentam pouca popularidade ou que são antipáticos para a maioria do grupo. Portanto, a estrutura social é vivenciada pela posição sociométrica da criança na interação com seus pares, isto é, a posição que o indivíduo ocupa no grupo social estabelece relações interpessoais em diversos contextos grupais, recurso essencial para novas possibilidades de interação e aceitação social (Castro et al., 2003; Cole \& Cole, 2003; Holfve-Sabel, 2014).

O mundo social é muitas vezes bastante exigente com as crianças. Pretende-se que coordenem um complexo processo social, elaborando de forma eficaz situações interpessoais difíceis, mobilizando-se para responder habilidades embaraçosas no grupo, sendo o principal fator responsável pela popularidade e/ou rejeição pelos pares (Lopes, Cruz \& Rutherford, 2002; Montiel, Pessotto \& Bartholomeu, 2014). O estudo de Coie, Dodge e Coppotelli (1982) destaca questões importantes de como a criança se integra no grupo de amigos ao investigar as seguintes questões: Com quais colegas você gostaria de estudar? Com quais colegas você não gostaria de estudar? De acordo com as respostas de aceitação ou rejeição, os autores identificaram as crianças como populares, rejeitadas, negligenciadas e controversas. Os alunos populares apresentam-se com elevado número de aceitação e baixo de rejeição; os rejeitados, com grande indicador de rejeição e baixo indicador de aceitação; os negligenciados, indicadores baixos ou nulos de escolha positiva e negativa; e os controversos, altos índices de indicação positiva e negativa (Morais, Otta \& Scala, 2001). É relevante ressaltar que Coie et al. (1982) enfatizam a utilização dos termos escolhas sociométricas positivas e negativas para discriminar fatores envolvidos no estudo do status social. Segundo os mesmos autores, a combinação das medidas (positiva e negativa) possibilita identificar os grupos de status sociais controverso e negligenciado.

As pesquisas sobre status sociométrico de alunos e sua relação no grupo têm se preocupado em relacionar os resultados com o desempenho acadêmico, as relações sociais ou problemas de comportamento. Morais et al. (2001), em pesquisa sobre competência social, verificaram atributos comportamentais de escolhas positivas e negativas, além da diferença de gêneros quanto à relação entre preferência/rejeição. Verificando a capacidade de adaptação e relacionamento no grupo, perceberam diferenças de gênero, indicando que os meninos foram mais avaliados por características sociais e as meninas por qualidades afetivas. A pesquisa indica que, na perspectiva de se estabelecer relações com os companheiros, fica evidente a importância do 
desenvolvimento psicossocial, mostrando que a aceitação social é um exercício para a vida em sociedade. Segundo Sisto (2005), Pavarini, Piazzarollo e Souza (2011), os meninos tendem a prejudicar os colegas com de agressão física e verbal, batendo ou ameaçando os outros. Com as meninas, a hipótese é de que são mais predispostas a concentrarem-se nas questões relacionais, que incluem comportamentos que podem comprometer amizades ou sentimentos que prejudiquem outro colega.

Destarte, o estudo de Molina e Del Prette (2008) investigou a aceitação de alunos com dificuldades de aprendizagem, avaliou os efeitos da promoção de habilidades sociais no status sociométrico negativo de crianças incluídas nos status rejeitado, negligenciado ou controvertido. Depois da intervenção, observou-se que $86 \%$ das crianças incluídas no grupo experimental com baixo desempenho acadêmico e status sociométrico negativo deixaram de ser rejeitadas ou negligenciadas, enquanto no grupo controle, que não passou por intervenção, $66 \%$ das crianças continuaram sendo representadas no status de rejeitadas.

Outro trabalho de investigação de Lemos e Meneses (2002), com o objetivo de avaliar a competência social de estudantes de $3^{\circ}$ e $6^{\circ}$ anos de escolaridade e explorar as dimensões da competência social em crianças portuguesas, evidenciou correlações negativas significativas entre habilidades sociais e problemas de comportamento, identificando que quanto maiores os problemas de comportamento mais pobres se apresentavam os repertórios de habilidades sociais, e vice-versa. Portanto, pode-se perceber que o status sociométrico em estudantes do Ensino Fundamental traz relações entre os domínios sociais e os problemas de comportamento, apontando para o risco social que podem sofrer as crianças que apresentam dificuldades nas relações entre seus pares. Um repertório de qualidade nas interações sociais traduz para o indivíduo a aquisição de conceitos positivos que possibilitam um melhor desenvolvimento social, diminuindo os efeitos da rejeição e dos problemas de comportamentos (Morais et al., 2001).

Em pesquisa realizada por Telles (2005), por meio de observações em sala de aula no $4^{\circ}$ ano de escolaridade, sobre os significados de gênero presentes nas relações entre crianças e formas de controle exercido pelos adultos, verificou-se que as atitudes tomadas tanto por alunos quanto por alunas não são distintas e, ao oposto de visões deterministas sobre padrões de comportamentos, não há uma natureza definida que padronize tais condutas. Segundo a pesquisadora, acreditar que os papéis femininos terão uma conduta determinada e diferente dos papéis masculinos, é considerar uma visão hierarquizada e estereotipada de gênero, pois induz a comportamentos que segregam os indivíduos, afetando as relações interpessoais.

Estudo realizado por Holfve-Sabel (2014) investigou os perfis de atitudes de estudantes populares e solitários, suas similaridades e diferenças, a relação com gênero e backgrounds culturais e as características da sala de aula reportadas pelos professores. Participaram 1.531 
estudantes de $6^{\mathrm{a}}$ série com média de idade de 12 anos da cidade sueca de Göteborg. Os alunos responderam instrumento de autorrelato constituído de 40 questões com cinco possibilidades de respostas, sendo a quinta a mais positiva. O estudo constatou que alunos populares e solitários apresentam as mesmas atitudes para com professores e escola. Contudo, estudantes solitários apresentaram mais atitudes negativas, ansiedade e problemas de relacionamento com colegas de turma. Os populares tiveram atitudes negativas ou neutras em relação aos aspectos escolares e pontuação negativa ou neutra para os relacionais.

Já a pesquisa de Titkova, Ivaniushina e Alexandrox (2013) investigou a relação da popularidade sociométrica com o desempenho acadêmico, considerando os diferentes níveis culturais e aspirações dos alunos no contexto de sala de aula. Participaram 5.058 alunos de escolas de Saint Pitisburgo, na Rússia. Os autores mostraram que o gênero é preditivo na relação entre desempenho acadêmico e popularidade. Os resultados apontaram que nas turmas em que a motivação para a aprendizagem é baixa o desempenho acadêmico dos meninos está negativamente relacionado à popularidade deles, enquanto que nas turmas com níveis acadêmicos e culturais mais elevados a relação é positiva.

$$
\text { Com efeito, entende-se que o }
$$

desenvolvimento humano resulta das aprendizagens em que crianças e jovens dominem conhecimentos que melhorem a capacidade reflexiva, desenvolvam a forma de pensar, destacando a necessidade do sujeito em desenvolver habilidades e competências, a fim de reorganizar o processo de construção do conhecimento. Baseando-se nessa perspectiva, as mudanças que aparecem no decorrer do desenvolvimento admitem que as interações sociais ofereçam desafios especiais na construção e transformação das etapas vivenciadas (Oliveira, Boruchovitch \& Santos, 2009). Para Oliveira et al. (2009), ao transpor essas etapas e adquirir novos conhecimentos, o indivíduo utiliza as informações que começam a ser processadas e armazenadas, auxiliando-o na organização de novas aprendizagens. Portanto, a transição do estudante para o $6^{\circ}$ ano provoca experiência de novos papéis sociais, estabelecendo relações interpessoais que auxiliam no domínio de habilidades cognitivas e sociais, na tomada de decisões e na busca pela independência (Cole \& Cole, 2003).

O desenvolvimento social de crianças na segunda infância, segundo Cole e Cole (2003), caracteriza-se por momentos de grande interação com seus companheiros, adquirindo atitudes diferentes diante da família, do estudo, dos amigos, atingindo sua autonomia psíquica e inserindo-se no meio social sem grandes interferências familiares. Nessa fase, conforme os autores, as crianças experimentam mais responsabilidades e mais liberdade, pois os adultos reconhecem uma capacidade e desenvoltura para atuarem e pensarem por si próprias. As experiências provocam a realização de novas atividades e o desempenho de novos papéis sociais, estabelecendo relações interpessoais que auxiliam no domínio de habilidades cognitivas e sociais, na tomada de decisões e na busca pela 
independência (Cole \& Cole, 2003). As interações sociais inerentes à vida escolar fazem parte das descobertas e encantamentos próprios do educando. Entretanto, a transição escolar nesse momento é de especial preocupação porque coincidem com o início da puberdade e com as mudanças de contexto que podem tornar esse período particularmente desafiador (Benner, 2011). Observa-se que a transição nos diferentes grupos sociais pode trazer acontecimentos ou eventos que são considerados especiais e singulares nas novas demandas de como aprender a lidar com o ambiente, fazer novos amigos, manter relações amistosas com adultos, nas quais estão presentes momentos que podem ser considerados um novo estágio para um processo de transição qualitativo de competências para lidar com as novas exigências (Benner, 2011).

A entrada para o $6^{\circ}$ ano significa almejar uma nova etapa para a autonomia e identidade social, mas também indica uma peculiaridade que está ligada ao processo de ensino e aprendizagem, envolvendo tanto os alunos que chegam à escola como os profissionais que lidam diretamente com eles (Barbosa, 2008). Portanto, o ingresso do estudante no segundo segmento do Ensino Fundamental traz demandas que levam o indivíduo a estabelecer novas competências e superar desafios exigidos pelo grupo, tanto no que diz respeito à competência social quanto à competência acadêmica (Marturano, Ferreira \& Gardinal, 2009). Para Morais et al. (2001), Lemos e Meneses (2002), Cole e Cole (2003), apesar da importância da transição de estudantes para o $6^{\circ}$ ano do Ensino Fundamental, são incipientes os estudos que exploram esse período escolar. Outrossim, a transição remete a processos multifacetados, nos quais não apenas variáveis cognitivas estão presentes, mas também aquelas que abarcam as relações afetivas e sociais (Montiel et al., 2014). Compreender como os alunos vivenciam esse processo muito contribuiria para ações pedagógicas e interacionais mais adequadas e que provavelmente facilitariam a aprendizagem, o estar na escola e na vida. Dessa forma, entendese a relevância de se investigar construtos relativos às habilidades sociais, à competência social, presentes no cotidiano da escola, com estudantes do $6^{\circ}$ ano e de alunos que frequentam o $7^{\circ}$ ano do Ensino Fundamental. Portanto, o estudo tem o objetivo de identificar e analisar o status sociométrico de estudantes, avaliando comportamentos que implicam nas habilidades sociais, visando verificar a aceitação/rejeição, inclusão ou exclusão social e a popularidade de alunos por seus colegas de turma. Além disso, foi objetivo também observar diferenças no comportamento dos estudantes, em relação ao gênero e na comparação com os alunos de $7^{\circ}$ ano.

\section{Método}

\section{Participantes}

Participaram 258 alunos (142 do $6^{\circ}$ ano e 116 do $7^{\circ}$ ano), sendo 124 do sexo feminino e 134 do masculino que frequentavam o Ensino Fundamental II da rede pública do Estado do Rio de Janeiro, com idades entre 10 e 13 anos $(M=11,62$ anos; $D P=0,88)$ para o $6^{\circ}$ e entre 11 e 
$15 \operatorname{anos}(M=12,75 ; D P=0,90)$ para o $7^{\circ}$ ano. Com relação ao estrato socioeconômico avaliado pelo Critério Brasil (Abep, 2015) $13 \quad(5,6 \%)$ encontravam-se no A1 e B1, respectivamente, 63 alunos $(27,7 \%)$ no B2, $104(42 \%)$ no C1 e 65 $(20 \%)$ no C2.

\section{Instrumentos}

Os alunos foram avaliados por meio do Protocolo de Indicação Sociométrica (Coie et al., 1982). Na aplicação desse instrumento, realizado individualmente, perguntou-se ao estudante: a) Quais as três crianças de sua sala com as quais você gostaria de fazer trabalhos em sala, brincar no ambiente escolar e estudar em casa e quais as três crianças de sua sala com as quais você não gostaria de fazer trabalhos em sala, brincar no ambiente escolar e estudar em casa?

\section{Procedimentos de coleta de dados}

A pesquisa foi realizada em uma escola da rede pública estadual localizada na região norte da cidade de Niterói, Rio de Janeiro, que atende crianças de 11 a 17 anos, alunos do $2^{\circ}$ segmento do Ensino Fundamental, advindos de diversos bairros adjacentes. A estratégia utilizada para a realização da pesquisa foi feita por meio de reunião de pais/responsáveis com esclarecimentos sobre a pesquisa e convidados a participar, além de visitas às turmas do $6^{\circ}$ e $7^{\circ}$ ano, convidando-os a participarem como voluntários. Depois da autorização, foi realizada a coleta de dados com os pais - a coleta de dados com os alunos foi realizada em sala de aula.

\section{Procedimentos éticos}

Os pais ou responsáveis assinaram o Termo de Consentimento Livre e Esclarecido para que os estudantes pudessem participar ativamente e estes assinaram o Termo de Assentimento. A pesquisa foi aprovada pelo Comitê de Ética e Pesquisa da Universidade Salgado de Oliveira (Parecer Projeto n. 71/2012).

\section{Procedimentos de análise de dados}

As perguntas do protocolo geraram a avaliação que produz os primeiros escores ("gosto mais" e "gosto menos") e em seguida impacto social (soma de "gosto mais" e "gosto menos") e preferência social (diferença entre "gosto mais" e "gosto menos"). A dimensão impacto social diz respeito a comportamentos ativos e proeminentes de valor negativo e positivo, enquanto a preferência social está relacionada à cooperatividade, apoio e atratividade física e negativamente relacionada à perturbação e agressão. Com isso, as dimensões possibilitam identificar as crianças que se inserem nos status apresentados (popular, rejeitado, controverso e negligenciado) ou em nenhum deles (sem categoria). A análise foi realizada segundo critérios estabelecidos por Molina e Del Prette (2008).

\section{Resultados}


A Tabela 1 apresenta a classificação dos alunos por turma como popular, rejeitado negligenciado, controvertido e sem categoria. A Tabela 2, em relação ao status sociométrico, constatou que os meninos $(11,2 \%)$ foram mais escolhidos como populares, mais votados como rejeitados (23,9\%), menos votados como negligenciados (2,2\%) e controvertidos (3,7\%). Esses indicadores sugerem que estudantes do $6^{\circ}$ ano apresentam mais avaliações por pares como rejeitados e populares.

Tabela 1. Classificação dos alunos por turma em popular, rejeitado, negligenciado, controvertido e total por sexo

\begin{tabular}{|c|c|c|c|c|c|c|c|c|c|c|}
\hline \multirow{2}{*}{$\begin{array}{l}\text { Variáveis } \\
\text { Turma }\end{array}$} & \multicolumn{2}{|c|}{ Popular } & \multicolumn{2}{|c|}{ Rejeitado } & \multicolumn{2}{|c|}{$\begin{array}{l}\text { Negligencia } \\
\text { do }\end{array}$} & \multicolumn{2}{|c|}{ Controvertido } & \multicolumn{2}{|c|}{ Sem Categoria } \\
\hline & $\mathbf{n}$ & $\%$ & n & $\%$ & $\mathbf{n}$ & $\%$ & $\mathrm{n}$ & $\%$ & $\mathbf{n}$ & $\%$ \\
\hline 601 & 4 & 15,4 & 2 & 7,7 & - & - & 4 & 15,4 & 16 & 61,5 \\
\hline 602 & 4 & 13,3 & 6 & $2-$ & - & - & - & - & 20 & 66,7 \\
\hline 603 & 1 & 3,6 & 4 & 14,3 & - & - & 1 & 3,6 & 22 & 78,6 \\
\hline 604 & 4 & 13,3 & 8 & 26,7 & 3 & $1-$ & 2 & 6,7 & 13 & 43,3 \\
\hline 605 & 5 & 17,2 & 6 & 20,7 & - & - & 1 & 3,4 & 17 & 58,6 \\
\hline 701 & 4 & 13,3 & 8 & 26,7 & - & - & - & - & 18 & 6 \\
\hline 702 & 1 & 3,6 & 3 & 10,7 & - & - & - & - & 24 & 85,7 \\
\hline 703 & 3 & 11,1 & 4 & 14,8 & - & - & 1 & 3,7 & 19 & 70,4 \\
\hline 704 & - & - & 5 & 16,7 & - & - & - & - & 25 & 83,3 \\
\hline $\mathbf{F}$ & 11 & 8,9 & 14 & 11,3 & - & - & 4 & 3,2 & 95 & 76,6 \\
\hline $\mathbf{M}$ & 15 & 11,2 & 32 & 23,9 & 3 & 2,2 & 5 & 3,7 & 79 & 59,0 \\
\hline
\end{tabular}

Nota. $\mathrm{F}=$ feminino; $\mathrm{M}=$ masculino.

Fonte: Elaborada pelas autoras.

Depois da normalização dos dados da sala de aula para cada um desses indicadores, obtiveram-se as seguintes classificações para a amostra total: os adolescentes do $6^{\circ}$ ano apresentaram escores superiores aos alunos do $7^{\circ}$ ano, sendo que $18(12,6 \%)$ foram considerados populares, sendo $8(44,4 \%)$ meninos e $10(55,5 \%)$ meninas; $26(18,18 \%)$ considerados rejeitados, sendo $17(65,4 \%)$ meninos e 9 (35,6\%) meninas; 3 $(2,09 \%)$ negligenciados, todos meninos; $8(5,6 \%)$ controvertidos, 4 (50\%) de cada sexo; considerados sem categoria, 87 (61,5\%) alunos, sendo $47(54 \%)$ meninos e $40(45,9 \%)$ meninas. Os alunos do $7^{\circ}$ ano tiveram escores inferiores, sendo $8(6,9 \%)$ alunos considerados populares, todos meninos; $20 \quad(17,4 \%)$ considerados 
rejeitados, $15(75 \%)$ meninos e $5(25 \%)$ meninas; 1 $(3,7 \%)$ menino na classificação controvertido; considerados sem categoria, 87 (74,7\%), sendo 35 $(40,2 \%)$ meninos e $52(59,7 \%)$ meninas. Em relação ao gênero, os valores obtidos podem ser interpretados como representando uma diferença entre os grupos de meninos e meninas, conforme os dados obtidos para os estudantes do sexo masculino e feminino apresentados nas Tabelas 2 e 3.

Tabela 2. Classificação dos alunos por turma e gênero quanto à média

\begin{tabular}{ccccccccccc}
\hline \multirow{2}{*}{$\begin{array}{c}\text { Variáveis } \\
\text { Turma }\end{array}$} & \multicolumn{2}{c}{ Popular } & \multicolumn{2}{c}{ Rejeitado } & \multicolumn{2}{c}{ Negligenciado } & \multicolumn{2}{c}{ Controvertido } & \multicolumn{2}{c}{ Sem Categoria } \\
\cline { 2 - 13 } & $\mathbf{M}$ & $\mathbf{F}$ & $\mathbf{M}$ & $\mathbf{F}$ & $\mathbf{M}$ & $\mathbf{F}$ & $\mathbf{M}$ & $\mathbf{F}$ & $\mathbf{M}$ & $\mathbf{F}$ \\
\hline 601 & 8 & 0,16 & 8 & - & - & - & 8 & 8 & 0,32 & 0,32 \\
602 & 6 & 6 & 0,1 & 0,1 & - & - & - & - & 0,3 & 0,4 \\
603 & - & 0,35 & 0,1 & 7 & - & - & - & 0,35 & 0,5 & 0,3 \\
604 & 0,1 & 0,33 & 0,2 & 0,1 & 0,3 & - & 0,1 & 0,1 & 0,13 & 0,3 \\
605 & 3 & 0,13 & - & 0,2 & - & - & 0,1 & 3 & 0,3 & 0,2 \\
701 & - & 0,13 & 0,1 & 0,2 & - & - & - & - & 0,13 & 0,5 \\
702 & - & 0,35 & 3 & 0,2 & - & - & - & - & 0,4 & 0,5 \\
703 & 7 & 4 & 7 & 0,11 & - & - & 3 & - & 0,3 & 0,3 \\
704 & - & - & 0,1 & 0,3 & - & - & - & - & 0,3 & 0,5 \\
\hline
\end{tabular}

Nota. $\mathrm{F}=$ feminino; $\mathrm{M}=$ masculino

Fonte: Elaborada pelas autoras.

Tabela 3. Avaliação da diferença entre as médias por ano de escolaridade, gênero e classificação

\begin{tabular}{lccccc}
\hline & $\begin{array}{c}\text { Popular } \\
\mathbf{M} / \mathbf{F}\end{array}$ & $\begin{array}{c}\text { Rejeitado } \\
\mathbf{M} / \mathbf{F}\end{array}$ & $\begin{array}{c}\text { Negligenciado } \\
\mathbf{M} / \mathbf{F}\end{array}$ & $\begin{array}{c}\text { Controvertido } \\
\mathbf{M} / \mathbf{F}\end{array}$ & $\begin{array}{c}\text { Sem Categoria } \\
\mathbf{M} / \mathbf{F}\end{array}$ \\
\hline $6^{\circ}$ ano & 0,15 & 7 & 83 & - & 7 \\
$7^{\circ}$ ano & 4 & 1 & 83 & 0,31 & 2,033 \\
\hline $\mathrm{p}<-5$ & & & \\
Nota. F = feminino; $\mathrm{M}=$ masculino \\
Fonte: Elaborada pelas autoras.
\end{tabular}

\section{Discussão}

A partir do diagnóstico do teste sociométrico com indicações positivas e negativas, observa-se que os estudantes do $6^{\circ}$ ano apresentaram mais avaliações por pares como rejeitados $\quad(88,7 \%)$, populares $(62,8 \%)$, controvertidos $(29,1 \%)$ e negligenciados $(1 \%)$. A 
dimensão do status social indicou o nível de aceitação e rejeição entre os colegas de turma, considerando que a avaliação permitiu identificar as posições relacionais de cada aluno no grupo, as escolhas, as rejeições recíprocas, os estudantes mais isolados, mais escolhidos, mais rejeitados, além da própria segregação dos grupos de meninas e de meninos, principalmente nas indicações positivas (Silva \& Löhr, 2001). A análise positiva e negativa dos alunos do $6^{\circ}$ ano é um importante indicador do funcionamento dos desempenhos sociais apresentados pelos estudantes diante de situações conflituosas. A capacidade para lidar com o estresse ou a frustração, com o baixo rendimento acadêmico, com as críticas, influencia os comportamentos que são aceitos ou negados entre os estudantes que participam do processo de interação (Del Prette \& Del Prette, 2009).

As frequências obtidas apresentam diferenças entre os grupos por gênero: meninos têm status de populares $(11,2 \%)$ e de rejeitados $(23,9 \%)$; meninas têm status de populares $(8,9 \%)$ e de rejeitadas (11,3\%). Broering e França (2008) e Sisto (2005) afirmam que comportamentos de agressão física são mais esperados nos meninos e as meninas esboçam com mais frequência a discussão de ideias. Os autores lembram ainda que, diferentemente das alunas, que são consideradas mais assertivas na forma de defender opiniões, os alunos esboçam reações no sentido de atrair a atenção do docente em sala de aula.

Da mesma forma, pode-se inferir que as indicações positivas em relação aos meninos vistas por seus pares como populares podem ter indicativos para comportamentos pró-sociais, sendo colaboradores, assertivos e mais empáticos (Coie et al., 1982). O comportamento pró-social facilita as relações entre as pessoas, neutralizando comportamentos considerados de risco social para a agressividade, delinquência e outros comportamentos desviantes (Silva \& Löhr, 2001).

Pavarini et al. (2011) afirmam que há correlações com avaliações positivas com atributos comportamentais positivos e nomeações negativas com atributos comportamentais negativos. Para os autores, é fato que crianças que apresentam mais comportamentos pró-sociais são mais aceitas e preferidas pelos colegas, e as que apresentam mais comportamentos antissociais sofrem mais rejeição dos colegas. Ademais, a competência social está positivamente associada à aceitação entre pares e as relações interpessoais saudáveis, sendo o desempenho social das crianças em situações de interação com colegas um preditor confiável da aceitação social. Os mesmos autores sinalizam que crianças tendem a apresentar preferência por pares do mesmo sexo e nomeação negativa para o sexo oposto, e que crianças do sexo feminino nomeiam negativamente mais colegas do sexo oposto, o que não é observado em meninos. Atentam ainda os autores para o fato de popularidade/liderança se apresentar positivamente relacionada à quantidade de nomeações positivas e negativamente associada à quantidade de nomeações negativas.

Sisto (2005) ressalta que as relações sociais em sala de aula de aceitação e rejeição não refletem diferenças associadas aos níveis socioeconômicos e sociais da escola, assim como o número de alunos atendidos e infraestrutura escolar oferecida. Mais recentemente, Montiel et al. 
(2014) destacaram que pode haver diferença quando se atende crianças advindas de instituições públicas situadas em bairros periféricos da região metropolitana, o que indicaria a importância de pesquisas nesse campo de investigação para maior detalhamento do fenômeno. Outrossim, os mesmos autores sugerem que as dimensões de habilidades sociais podem estar relacionadas à diminuição da rejeição no grupo do que necessariamente à própria aceitação, o que supostamente remete à possibilidade de que outras variáveis também estejam presentes na aceitação (personalidade, socialização). Entende-se, portanto, que as percepções das condutas negativas entre os estudantes de $6^{\circ}$ e $7^{\circ}$ anos presumivelmente estabeleceram as escolhas de rejeição entre os colegas. Destaca-se a importância que mudanças ocorram na vida dos alunos para que esse processo não crie marcas dolorosas, dificultando a adaptação socioafetiva como adolescentes e adultos (Silva \& Löhr, 2001).

Em termos de frequência e ano de escolaridade, os alunos do $7^{\circ}$ ano indicam desenvolvimento afetivo e social, demonstrado uma ampliação na dinâmica das relações entre os pares (populares 3,1\%). Os estudos apresentados reforçam a ideia de que, em geral, à medida que o indivíduo se desenvolve, as situações difíceis vão sendo resolvidas com mais autonomia, ampliando o grau de percepção de si e de seus pares (Del Prette \& Del Prette, 2009). A pesquisa também apresentou dados importantes de alunos que não apresentaram status sociométrico, permanecendo sem categoria (meninos 13,6\% e meninas 18,6\%). Pode-se perceber que esses alunos estão adaptados ao grupo social, demonstrando comportamentos amigáveis, realizando formas positivas de interação social.

Para se descrever as diferenças entre os grupos, alguns procedimentos do status sociométrico ajudam a construir o perfil dos estudantes quanto aos aspectos sociais, psicológicos e acadêmicos. O grupo considerado popular apresenta comportamentos cooperativos e manifestam relações sociais mais competentes, apresentando liderança positiva. Os rejeitados estão na categoria dos briguentos e destrutivos e apresentam baixo nível de preferência social e alto nível de impacto social, sempre em desagrado com os pares. O grupo considerado negligenciado tende a sentir medo, apresenta isolamento social, timidez, sendo muitas vezes ignorado em sala de aula e no ambiente escolar. Os controvertidos apresentam comportamentos sociais oscilantes, ora de estima, ora indesejável, demonstrando possíveis transtornos de comportamento (Molina \& Del Prette, 2007).

Os resultados encontrados no teste sociométrico das turmas de $6^{\circ}$ e $7^{\circ}$ anos podem indicar que os relacionamentos vão se construindo à medida que os estudantes começam a associar e desenvolver formas adaptativas no relacionamento social. Segundo Del Prette \& Del Prette (2009), os comportamentos adaptativos se referem a desempenho acadêmico, cooperação, responsabilidade para realizar tarefas, podendo estar associados à competência social e desempenho acadêmico. Para os alunos do $6^{\circ}$ ano, as situações se apresentam como novas no ambiente escolar, precisando fazer novos amigos, 
ser aceito entre os pares, adquirindo competências para lidar com as novas demandas. Para os alunos do $7^{\circ}$, ano esse ambiente já é mais conhecido e começam a desenvolver um comportamento socialmente mais competente, se relacionando melhor, como mostra o resultado do teste sociométrico, que indica que houve um maior desenvolvimento das relações afetivas e sociais, apresentando menor índice de rejeição (17,4\%) que os alunos do $6^{\circ}$ ano $(18,2 \%)$.

\section{Considerações finais}

Os resultados relativos ao status sociométrico acerca dos papéis sociais entre os estudantes indicam particularidades no comportamento do $6^{\circ}$ ano, apresentando comportamentos de rejeição, de popularidade, comportamentos controvertidos e status negligenciados. É importante que estudantes adquiram capacidade de interagir com o grupo social, pois essas interações vão contribuir para um desenvolvimento psicossocial sadio, estabelecendo com seus pares condições de pertencimento e mecanismos de aceitação indispensáveis para uma melhor adaptação.

Algumas limitações do estudo se apresentam, entre elas encontra-se o fato de os estudos terem sido feitos na mesma escola, o que pode ter restringido os resultados de outras realidades acadêmicas. Em relação aos dados sociométricos, é importante utilizá-los como resultados comparativos e longitudinais, apontando que não devem ser descritos como resultados conclusivos, pois os grupos sociais estão sempre em desenvolvimento e não podem ser vistos de forma independente e isolada. É importante que os dados do teste sociométrico sejam relacionados a outros dados experimentais, como observações dos professores e pais para melhorar a compreensão do status do grupo e sua estrutura social.

Dessa forma, a pesquisa permitiu perceber que as relações de gênero presentes no ambiente escolar discutem os comportamentos de preferência e rejeição entre meninos e meninas do Ensino Fundamental do $6^{\circ}$ e do $7^{\circ}$ anos. Nessa perspectiva, foi evidenciado que além de os meninos terem apresentado status social negativo e comportamentos de rejeição que indicam problemas de oposição e agressividade nas relações sociais, superaram o status das meninas em relação à popularidade, cooperação e aceitação, liderando de forma positiva a sua relação grupal.

As observações da pesquisa permitem compreender nos grupos relações entre as habilidades sociais dos adolescentes e os problemas de comportamento, especialmente nos grupos de status sociais controversos e negligenciados. O fato de os meninos terem características positivas que podem reparar as negativas conduz à ideia de que quanto mais cedo se identificar dificuldades de ajustamento social, mais rapidamente se poderá interferir e estabilizar comportamentos antissociais.

$$
\text { Destarte, sugerem-se estudos }
$$
longitudinais com o intuito de acompanhar a estreita relação entre gêneros e habilidades sociais, conduzindo também para observações diretas do comportamento dos estudantes, percebendo a 
dimensão de preferência e rejeição social e facilitando o desempenho nas relações acadêmicas.

\section{Referências}

Barbosa, A. R. (2008). A relação estado/município na passagem da $4^{a}$ para a $5^{a}$ série em Curitiba. Dissertação de mestrado, Universidade Federal do Paraná, Paraná, Brasil.

Benner, A. D. (2011). The Transition to High School: Current Knowledge, Future Directions. Educational Psychology Review, 23(3), 299-328.

Broering, C. V., \& França, G. R. (2008). Diferenças comportamentais de gêneros em espaços estruturado e não-estruturado. Psicologia para a América Latina, 13.

Camargo, S. P. H, \& Bosa, C. A. (2009). Competência social, inclusão escolar e autismo: revisão crítica da literatura. Psicologia \& Sociedade, 21(1), 65-74.

Castro, R. E. F., Melo, M. H. S., \& Silvares, E. F. M. (2003). O julgamento de pares de crianças com dificuldades interativas após um modelo ampliado de intervenção. Psicologia: Reflexão e Crítica, 16(2), 309-318.

Cia, F., \& Costa, C. S. L. (2013). Desempenho acadêmico nas séries do ensino fundamental: relação com $\mathrm{O}$ desenvolvimento social. Psicologia Argumento, 30(68), 109-118.
Coie, J. D., Dodge K. A., \& Coppotelli, H. (1982). Dimensions and Types of Social Status: a cross-age perspective. Developmental Psychology, 18(4), 557-570.

Cole, M., \& Cole, S. (2003). O desenvolvimento da criança e do adolescente. Porto Alegre: ArtMed.

Del Prette, A., \& Del Prette, Z. A. P. (2003). Habilidades sociais, desenvolvimento $e$ aprendizagem: questões conceituais, avaliação $e$ intervenção. São Paulo: Alínea Editora.

Del Prette, A., \& Del Prette, Z. A. P. (Orgs.). (2011). Habilidades sociais: intervençôes efetivas em grupo. São Paulo: Casa do Psicólogo.

Del Prette, Z. A. P., \& Del Prette, A. (1999). Psicologia das Habilidades Sociais: terapia, educação e trabalho. Rio de Janeiro: Vozes.

Del Prette, Z. A. P., \& Del Prette, A. (2009). Psicologia das Habilidades Sociais na Infância: teoria e prática. Rio de Janeiro: Vozes.

Elliot, S. N., Sheridan, S. M., \& Gresham, F. M. (1989). Assessing and Treating Social Skills Deficits: A Case Study for the ScientistPractitioner. Journal of School Psychology, 27, 197-222.

Ferreira, H. I. M. M. (2000). A competência social no contexto escolar: um estudo da interface entre a competência social e a realização académica na criança. Dissertação de mestrado, Universidade do Porto, Porto, Portugal. 
Garcia, A. (2005). Psicologia da amizade na infância: uma revisão crítica da literatura recente. Interação em Psicologia, 9(2), 285-294.

Holfve-Sabel, M. (2014). Students' Individual Choices of Peers to Work with During Lessons May Counteract Segregation. Social Indicators Research, 122, 1-18. doi:10.1007/s11205-014-0693-8.

Lemos, M. S., \& Meneses, H. I. (2002). A avaliação da competência social: versão portuguesa da forma para professores do SSRS. Psicologia: Teoria e Pesquisa, 18(3), 267274.

Lopes, J., Cruz, C., \& Rutherford, R. B. (2002). The Relationship of Peer Perceptions to Student Achievement and Teacher Ratings of 5th and 6th Grade Students. Education and Treatment of Children, 25, 476-495.

Montiel, J. M., Pessotto, F., \& Bartholomeu, D. (2014). Habilidades sociais e status sociométrico em crianças do ensino fundamental. Revista Sul Americana de Psicologia, 2(2), 251-273.

Molina, R. C. M., \& Del Prette, A. (2007). Mudança no status sociométrico negativo de alunos com dificuldades de aprendizagem. Psicologia Escolar e Educacional, 11(2), 299310.

Morais, M. L. S., Otta, E., \& Scala, C. T. (2001). Status sociométrico e avaliação de características comportamentais: um estudo de competência social em pré-escolares. Psicologia: Reflexão e Crítica, 14(1), 119-131.

Mota, C. P., Matos. P. M., \& Lemos, M. S. (2011). Psychometric Properties of the Social Skills Questionnaire: Portuguese Adaptation of the Student Form (Grades 7 to 12). The Spanish Journal of Psychology, 14(1), 486-499.

Neves, F. A., Castanheira, M. L., \& Gouvêa, M. C. S. (2015). O letramento e o brincar em processos de socialização na educação infantil: brincadeiras diferentes. Revista Brasileira de Educação, 20(60), 215-244. doi.org/10.1590/S1413-24782015206011.

Oliveira, K. L., Boruchotvitch, E., \& Santos, A. A. A. (2009). A técnica de Cloze na avaliação da compreensão em leitura. In A. A. A. Santos, E. Boruchovitch \& K. L. Oliveira (Orgs.). Cloze: um instrumento e diagnóstico e intervenção (pp. 47-70.). São Paulo: Casa do Psicólogo

Pavarino M. G., Del Prette, A., \& Del Prette, Z. A. P. (2005). O desenvolvimento da empatia como prevenção da agressividade na infância. Psico, 36(2), 127-134.

Pavarini, G., Piazzarollo, C. L., \& Souza, D. H. (2011). Compreensão de emoções, aceitação social e avaliação de atributos comportamentais em crianças escolares. Psicologia: Reflexão e Crítica, 24(1), 135-143.

Ruegg, E. (2003). Social Competence, Transition Plans and Children with Learning 
Disabilities. Essays in Education, 7, 1-8.

Recuperado em 12 março, 2017, de http://www.usca.edu/essays/vol7fall2003. html.

Silva, V. R. M. G., \& Löhr, S. S. (2001). Indicadores de rejeição em grupo de crianças. Interação em Psicologia, 5, 9-30.

Sisto, F. F. (2005). Aceitação-rejeição para estudar e agressividade na escola. Psicologia em Estudo, 10(1), 117-125.

Stevanato, I. S., Loureiro, S. R., Linhares, M. B. M., \& Marturano, E. M. (2003). Autoconceito de crianças com dificuldades de aprendizagem e problemas de comportamento. Psicologia em Estudo, 8(1), 67-76.

Telles, E. O. (2005). As relações de gênero nos tempos e espaços escolares: estudo etnográfico em uma escola pública de São Paulo. Dissertação de mestrado, Universidade do Estado de São Paulo, São Paulo, Brasil.

Titkova, V., Ivaniushina, V., \& Alexandrov, D. (2013). Sociometric Popularity in a School Context. National Research University Higher School of Economics, 10, 1-30. doi $10.2139 /$ ssrn.2227302.

Recebido em: 17/12/2017

Aprovado em: 30/7/2018 